\title{
EFFECTS OF TRIPARANOL (MER-29) ON CHOLESTEROL BIOSYNTHESIS AND ON BLOOD STEROL LEVELS IN MAN *
}

\author{
By DANIEL STEINBERG, JOEL AVIGAN AND EUGENE B. FEIGELSON \\ (From the Laboratory of Cellular Physiology and Metabolism, National Heart Institute, \\ Bethesda, $M d$.
}

(Submitted Novmeber 18, 1960 ; accepted January 19, 1961)

The possibility of reducing elevated blood cholesterol levels with agents that inhibit endogenous biosynthesis of cholesterol is an attractive one, since dietary treatment is sometimes difficult to achieve and almost always difficult to maintain. Some of the theoretical aspects of such an approach have been outlined $(3,4)$, and the feasibility of the approach has been established in experimental animals. For example, it has been shown that $\Delta^{4}$-cholestenone, a potent inhibitor of cholesterol biosynthesis (5), can indeed lower levels of blood cholesterol $(3,6)$. Unfortunately, the feeding of $\Delta^{4}$-cholestenone in man and animals leads to accumulation of dihydrocholesterol in the serum (7) and this latter compound is known to be itself atherogenic (8). Certain other inhibitory substances have been explored but either have proved to be relatively ineffective $(9,10)$ or have not yet been adequately tested clinically $(11,12)$.

In 1959 Blohm, MacKenzie, Kariya and Laughlin at the William S. Merrell Company reported their finding of a new inhibitor of cholesterol synthesis, MER-29 (1-[ $p$ - $\beta$-diethylaminoethoxy) phenyl]-1-( $p$-tolyl)-2-( $p$-chlorophenyl) ethanol). Their studies indicated that the compound blocked synthesis at some point subsequent to the formation of lanosterol (13) and that serum and tissue levels of cholesterol were reduced in experimental animals (14). Animal studies in this laboratory demonstrated the accumulation of desmosterol (24-dehydrocholesterol) in the tissues of MER29-treated animals, and a series of isotopic studies established that the major site of action of the drug was at the last step in cholesterol biosynthesis-namely, in the reduction of desmosterol to

* Preliminary reports of this work were presented at the Conference on MER-29 (Triparanol), December 1959, Princeton, N. J. (1) and at the meetings of the Federation of American Societies for Experimental Biology, April 1960, Chicago, Ill. (2). cholesterol $(1,15,16)$. The present paper reports clinical studies which show that the mechanism of action in man is similar to that in animals. The degree of accumulation of desmosterol in the serum of treated patients and the changes in cholesterol level are reported. The analytical problems involved in determining serum desmosterol levels are discussed, and the feasibility of using gas-liquid chromatography for separation of desmosterol and cholesterol is demonstrated. Finally, the rates of esterification of serum desmosterol and serum cholesterol are compared.

\section{METHODS}

Patients were admitted to a metabolic ward of the Clinical Center and placed on an isocaloric diet of constant composition (three patients, studied in the outpatient department, followed a prescribed low animal fat diet, but its composition was not measured). The patients were maintained on their diets for a period of at least 2 weeks before treatment was begun. Then MER-29 was given orally in a single daily dose of either 100 or 250 mg.

Blood samples from the antecubital vein were taken in the morning, two or three times a week, after an overnight fast. The serum samples were analyzed for cholesterol and desmosterol as described below.

Determination of cholesterol and desmosterol in serum. Sera were extracted with 25 vol of $1: 1$ alcohol: acetone (vol/vol) and the free sterols were precipitated from aliquots of these extracts as digitonides. Other aliquots were treated with $\mathrm{KOH}$ for 1 hour at $40^{\circ} \mathrm{C}$, neutralized with acetic acid and the total sterols were precipitated as digitonides. The sterol digitonides derived from the free and the total sterol fractions were washed with 50 per cent aqueous alcohol, 2:1 ether:acetone (vol/vol) and ether, and dried. The precipitates were cleaved with dry pyridine at $100^{\circ} \mathrm{C}$ for 10 to 30 minutes. Twenty vol of ether was then added, the precipitated digitonin was separated by centrifugation and the precipitate was washed once with ether. The pooled ether supernatants were taken to dryness and the sterols were re-extracted with dry ether, which was again removed by evaporation. The sterols were determined by the method of Abell, Levy, Brodie and Kendall (17) modified to permit separate estimation of cholesterol and desmosterol, as described in 
detail elsewhere (18). This method depends on reading the optical densities of the products of the LiebermannBurchard reaction at $635 \mathrm{~m} \mu$ after 35 minutes and at $420 \mathrm{~m} \mu$ after 90 minutes. Calculation of the amounts of cholesterol and desmosterol present is based on the different absorption spectra of the colored products derived from the two sterols. Standards of pure cholesterol and desmosterol were analyzed with each series of determinations. Pure desmosterol was obtained, either by isolation from livers of rats fed MER-29 (18) or synthetically from 25-norketocholesterol by methylation with a Grignard reagent and dehydration of the resulting 25-hydroxycholesterol 1 (19).

Radioisotopic studies. On the mornings when radioisotopic studies were initiated, food was withheld until after the collection of the 4-hour blood sample. Twentyfive $\mu \mathrm{c}$ of a saline solution of $2-\mathrm{C}^{14}$-mevalonic acid (approximately $8 \mathrm{mg}$ ) was rapidly injected into the antecubital vein. Blood samples were taken at $1,2,3,4,12$, and 24 hours, the first samples from the opposite arm. In one study samples were also taken at 7, 14, and 21 days.

The free sterols were precipitated as digitonides from extracts of 10 to $50 \mathrm{ml}$ of serum and the precipitate was washed as described for the analytical determination. The combined supernatant and washes were evaporated to dryness and the residue was saponified in ethanolic $\mathrm{KOH}$. The nonsaponifiable materials were extracted with heptane and the extract was backwashed with water. The heptane extract was taken to dryness, the residue was redissolved in ethanol and the sterols were precipitated with digitonin and washed as usual. The digitonides of both the free and the esterified sterol fractions were subsequently cleaved with pyridine and extracted with ether as described above. Small aliquots of these samples were taken for counting of radioactivity and for colorimetric determination, which permitted the calculation of the specific radioactivities of the unfractionated free and esterified sterols. In some studies the cholesterol and desmosterol in both free and ester sterol fractions were separated by chromatography of their yellow-colored $p$-phenylazobenzoyl esters on columns of silicic acid: Celite $2: 1(20)$. Some of the samples to be chromatographed contained only 5 to $10 \mathrm{mg}$ of total sterols, and small columns, $8 \mathrm{~mm}$ in diameter, had to be used. On this small scale complete separation of the two sterol bands was not obtained. After the yellow ester zone had run almost to the bottom of the column, the silicic acid cylinder was mechanically extruded and slices were taken from the slowest and fastest moving portions. These zones were individually extracted with benzene. After saponification in methanolic $\mathrm{KOH}$, the sterols were extracted with heptane, washed with water and divided into two aliquots for counting of radioactivity and for colorimetric determination of cholesterol and desmosterol. Knowing the analytical values for the two sterols in the samples counted, it was possible to calcu-

1 The authors wish to thank Dr. E. Mosettig and Mr. R. T. Brown for preparing the synthetic material.

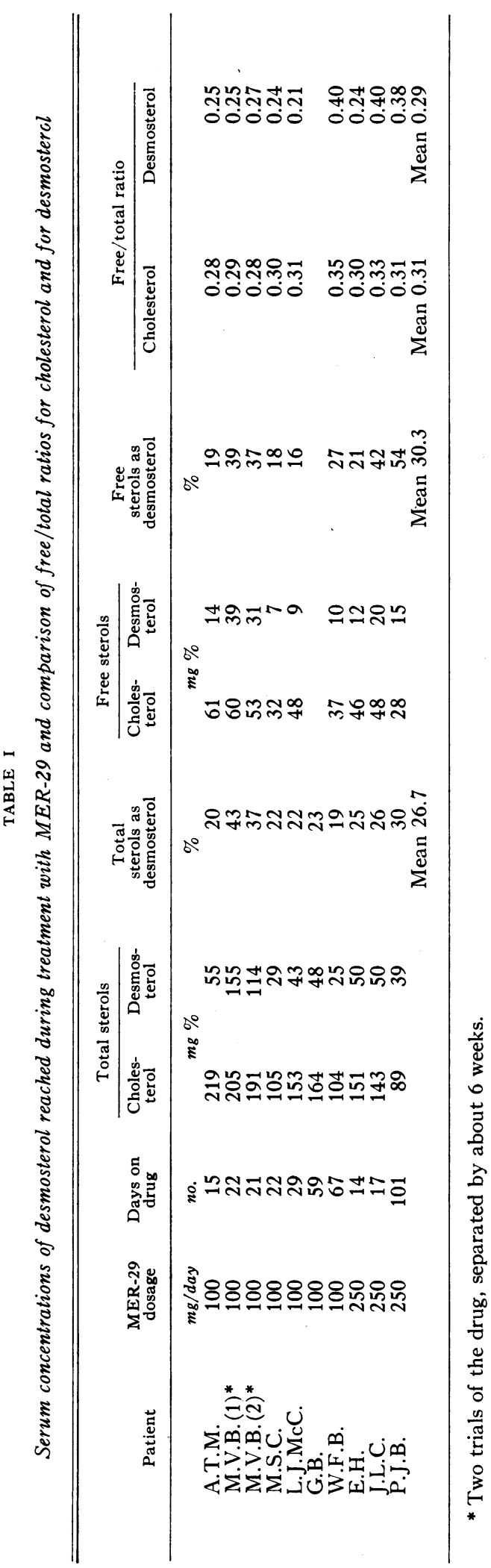


late the two specific radioactivities individually, even though the desmosterol was contaminated with a small amount of cholesterol and vice versa.

Separation of sterols by gas-liquid chromatography was done according to vanden Heuvel, Sweeley and Horning (21). The column was packed with Chromosorb W, coated with silicone rubber (G.E. SE-30). The chromatographic runs were carried out at $220^{\circ} \mathrm{C}$.

\section{RESULTS}

As shown in Table I, all patients treated with MER-29 had desmosterol in their serum. On the other hand, attempts to demonstrate desmosterol in normal serum, both by column chromatography of $p$-phenylazobenzoyl esters of the total sterol fraction and directly by gas-liquid chromatography, were unsuccessful. The sensitivity of these methods as applied is such that the level of desmosterol in normal serum can be no greater than 0.1 per cent of the total sterols. During MER-29 treatment, in most patients the serum desmosterol reached a level of between 25 and $55 \mathrm{mg}$ per 100 $\mathrm{ml}$, or on the average, about 27 per cent of the total circulating sterols. Patient M.V.B. showed quite a distinctive response, reaching desmosterol levels of 155 and $114 \mathrm{mg}$ per $100 \mathrm{ml}$, respectively, in two separate trials of the drug at $100 \mathrm{mg}$ per day. In this case the desmosterol in the serum represented about 40 per cent of the total circulating sterols.

The time course of the appearance of desmosterol in the serum is typified by the results shown

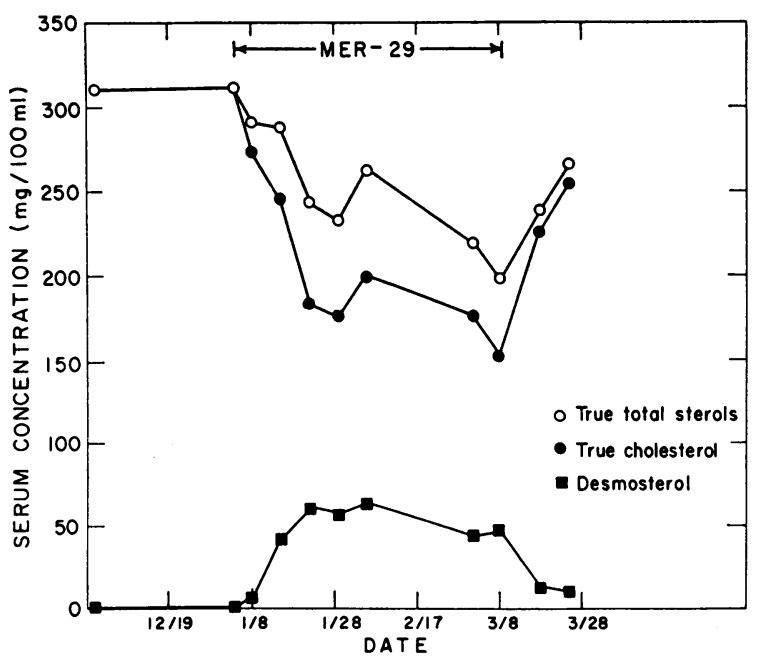

Fig. 1. Time course of SERUM ChOlesterol and desmosterol CONCENtrations in Patient G.B. ReCEIVING MER-29.

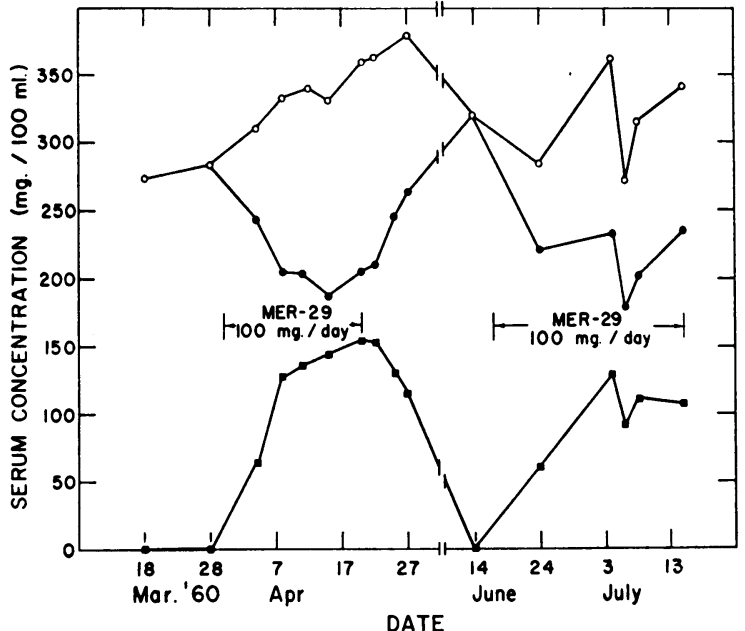

Fig. 2. Time COURSE OF SERUM ChOlesterol AND desmosterol concentrations in Patient M.V.B. ReCeiving MER-29 in two Separate trials. Symbols the same as those in Figure 1.

in Figure 1. The desmosterol concentration rose rather quickly after the start of treatment, reached a plateau in about 2 weeks and then remained flat during continued treatment. Within 2 weeks after discontinuing the drug, desmosterol had disappeared from the serum. There was no evidence for continuing accumulation of desmosterol in the serum, and after a period of drug treatment it reached a fairly constant level characteristic for each patient. A similar time course in two separate trials of the drug in Patient M.V.B. is shown in Figure 2.

Although there was some variability, the relative amounts of desmosterol present in the free sterol fraction and the relative amounts of desmosterol in the total sterol fraction (averages 30.3 and 26.7 per cent, respectively) were comparable. As can be seen in Table I, the free to total ratio for circulating desmosterol was not significantly different from the free to total ratio for circulating cholesterol.

Evaluation of changes in serum sterol levels. As has been previously reported (1), the color yield of desmosterol in the Liebermann-Burchard reaction is only about 60 per cent of the color yield given by cholesterol. Consequently, use of this method, the basis of most clinical procedures for serum sterol analysis, will give misleading results in patients under treatment with MER-29. In the present studies, use was made of the differen- 
tial colorimetric method of Avigan and co-workers (18) to determine the true levels of cholesterol and desmosterol.

Preliminary results using gas-liquid chromatography (21) suggest the usefulness of this technique, when available, for estimating desmosterol in the serum. ${ }^{2}$ An analytical record obtained of the total digitonin-precipitable sterol fraction of a patient under treatment with MER-29 is shown in Figure 3. Cholesterol emerged first with a retention time of 36 minutes and desmosterol followed, with a retention of 39.7 minutes. Because of an overlap and some tailing, precise measurement of relative concentrations was not possible, but the calculated results agreed well with those obtained on the same sample using the differential colorimetric method. Different liquid phases and different conditions for chromatography are under study in attempts to improve this resolution. It is of interest to note that at the sensitivity employed no sterols other than desmosterol and

2 We acknowledge with thanks the helpful assistance of Dr. W. J. A. vanden Heuvel, Dr. E. C. Horning and Dr. A. Karmen in these gas-liquid chromatographic studies.

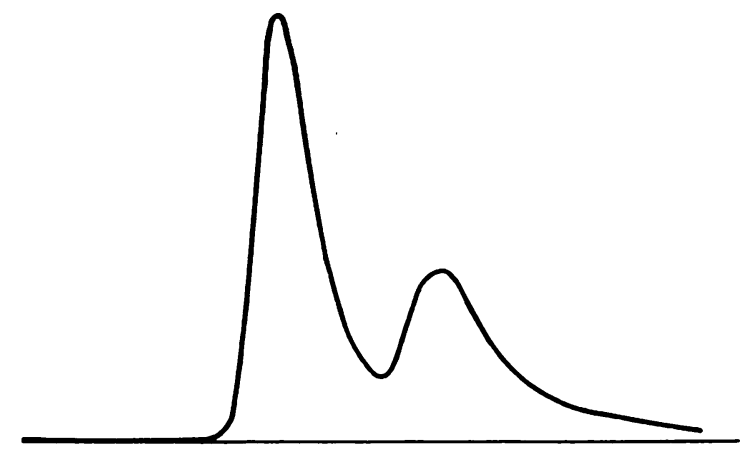

Fig. 3. Gas Chromatogram of Sterols isolated From Serum of Patient M.V.B. treated with MER-29. The larger peak, cholesterol; the smaller, desmosterol.

cholesterol were detected in the digitonin-precipitable fraction of this patient's serum.

The true cholesterol levels in patients during control periods and under treatment with MER-29 are summarized in Table II. The nature of the diet is indicated in the last column of the table. Every patient showed a marked drop in true cholesterol level; the absolute changes ranged from 39 to $131 \mathrm{mg}$ per $100 \mathrm{ml}$ (average 83); the percentage changes ranged from 18.9 to 46.3 per cent (mean 34.0). It should be noted that neither the

TABLE II

Changes in true * total serum sterol levels and changes in apparent $\dagger$ (Liebermann-Burchard) serum sterol levels with MER-29 treatment

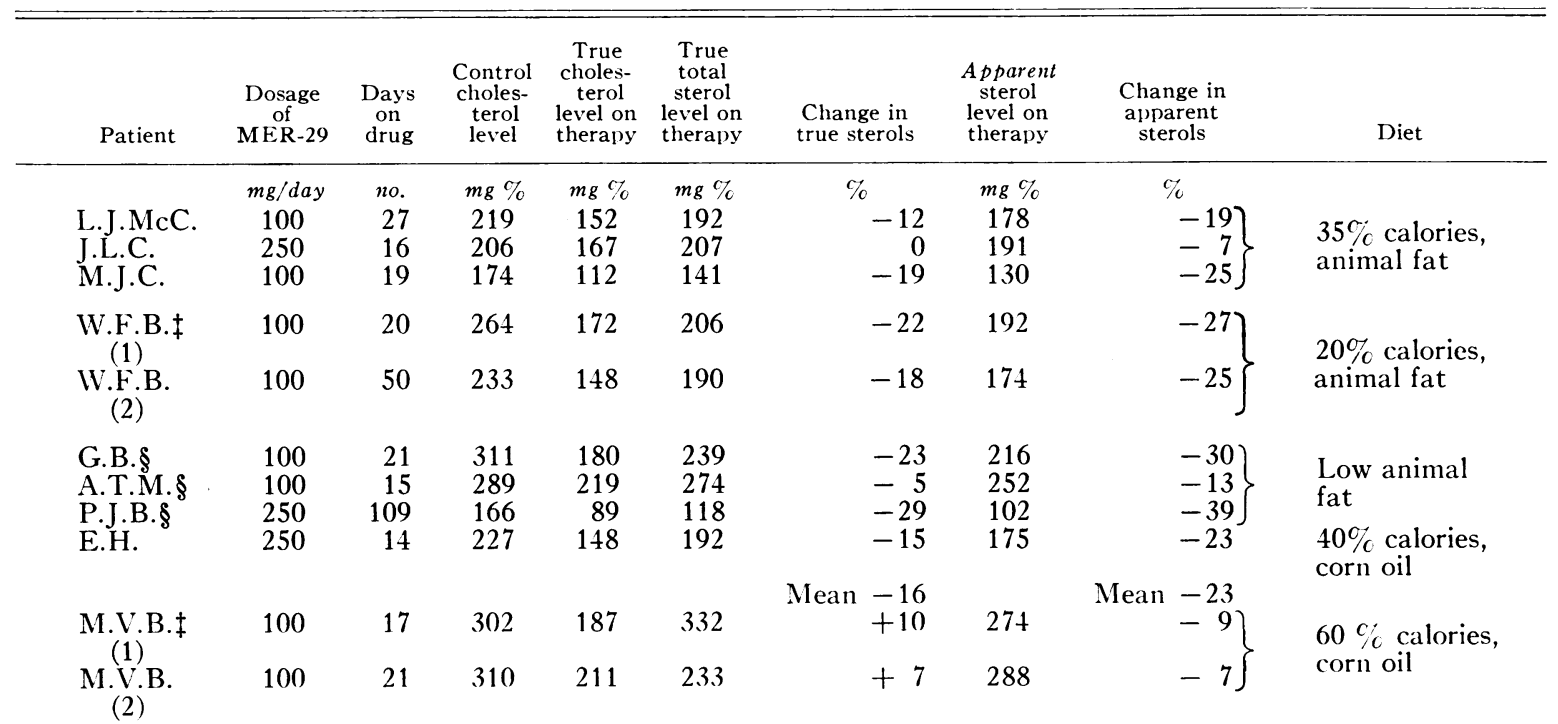

* Determined by the differential colorimetric method described in the text.

$\dagger$ Value that would have been obtained based on color yield of cholesterol alone.

$\ddagger$ These patients had two independent trials on the drug separated by several months.

$\S$ Outpatients. 
TABLE III

Comparison of specific radioactivities of serum free desmosterol and serum free cholesterol 4 hours after intravenous injection of 2-C ${ }^{14}$-mevalonic acid in patients under treatment with MER-29

\begin{tabular}{ccc}
\hline \hline & \multicolumn{2}{c}{ Specific radioactivity } \\
\cline { 2 - 3 } $\begin{array}{c}\text { Experi- } \\
\text { nent }\end{array}$ & $\begin{array}{c}\text { Free desmos- } \\
\text { terol }\end{array}$ & $\begin{array}{c}\text { Free choles- } \\
\text { terol }\end{array}$ \\
\hline & \multicolumn{2}{c}{${ }^{c p m / m g}$} \\
1 & 1,765 & 11 \\
2 & 1,949 & 0 \\
3 & 838 & 62 \\
\hline
\end{tabular}

absolute nor the relative changes in cholesterol level were distinctly different in the patients consuming animal fat (containing from 600 to 1,000 $\mathrm{mg}$ of cholesterol daily) from the changes seen in patients on corn oil formula (containing virtually no cholesterol).

Because of the simultaneous accumulation of desmosterol in the serum, the changes in true total serum sterol level were much less striking. Six patients showed a drop, in one there was no change, and in one there was actually a rise (Table II). The results of individual time course studies in Patient W.F.B., whose response was fairly typical, and in Patient M.V.B., whose total sterol level rose under treatment, are shown in Figures 1 and 2 , respectively. If the results in Patient M.V.B. are excluded and the results of the two separate trials in Patient W.F.B. are averaged, the mean drop in true total serum sterol level was 15 per cent. If all the results are grouped together the mean drop was 11 per cent.

The calculated changes in apparent sterol level that would have been obtained using standard clinical methods based on the Liebermann-Burchard color reaction are also shown in Table II. Because of the lower color yield given by desmosterol, the apparent changes are greater, averaging 23 per cent if Patient M.V.B. is excluded or 21 per cent for the group as a whole.

It is pertinent to note that there was a drop in apparent sterol level in the case of Patient M.V.B. even though the true sterol level actually rose slightly.

Radioisotopic studies. In patients under treatment with MER-29, the specific radioactivity of serum free desmosterol 4 hours after intravenous injection of $2-\mathrm{C}^{14}$-mevalonic acid was at least an order of magnitude higher than the specific ra- dioactivity of serum free cholesterol (Table III), compatible with a precursor product relationship. The data shown in Figure 4, from a study in which the specific radioactivities of the two sterols were followed for 3 weeks after injection of labeled mevalonate, also support the conclusion that desmosterol is an immediate percursor of cholesterol. The specific radioactivity of desmosterol remained higher than that of cholesterol for about 2 weeks, at which point the specific radioactivity curves intersected. These results support the interpretation that in man, as in experimental animals, the drug effectively blocks the reduction of desmosterol to cholesterol. That the inhibition of this reaction is quite marked is shown by the length of time taken for the curves of specific radioactivity to cross.

As shown in Figure 4, the curve of specific radioactivity of ester desmosterol rose during the first 48 hours after injection of $2-\mathrm{C}^{14}$-mevalonate, crossed the curve for free desmosterol and then fell in parallel with, but slightly above it. The relation between the curves is that of precursor and

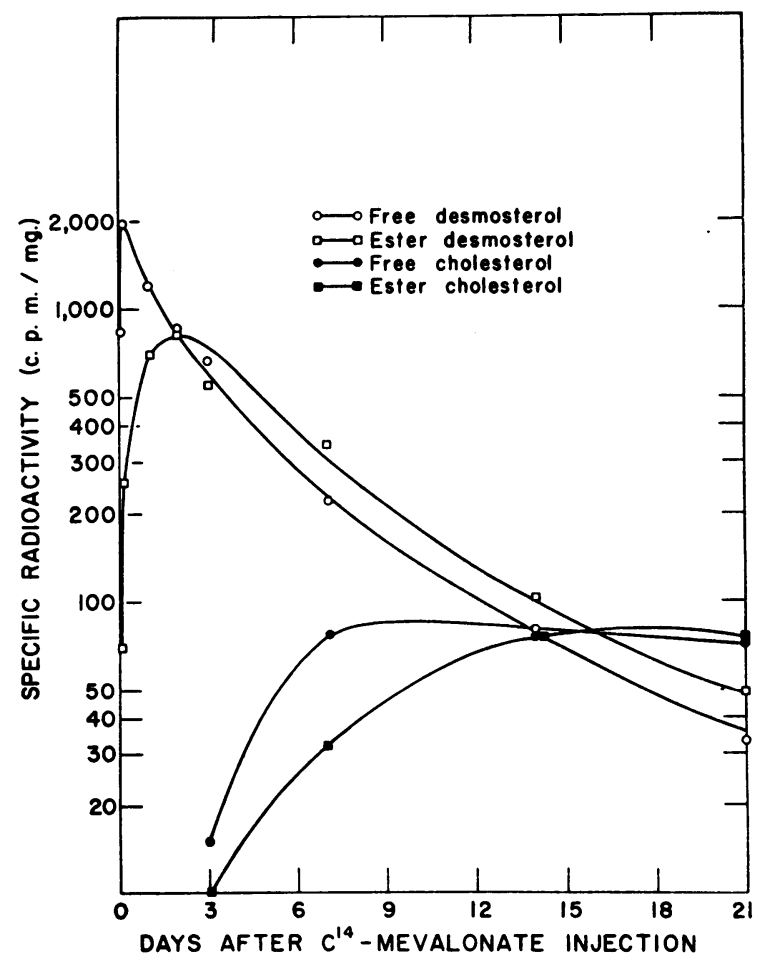

Fig. 4. SPECIFIC RADIOACTIVITY OF FREE AND ESTERIFIED DESMOSTEROL AND CHOLESTEROL IN SERUM OF PATIENT W.F.B. FOLLOWING THE ADMINISTRATION OF $\mathrm{C}^{14}$ MEVALONIC ACID. 
product (22). The rate of conversion of free desmosterol to ester desmosterol appears to be quite similar to that reported for cholesterol by Hellman (23) and Eckles (24), and their coworkers and is confirmed in the control studies reported below.

A series of experiments was carried out, in which the rate of appearance of radioactivity from injected 2-C $\mathrm{C}^{14}$-mevalonate was determined during drug treatment and during a control period. Each patient served as his own control in these studies. The specific radioactivity of the unfractionated digitonin-precipitable sterols was determined in the hope of establishing whether or not the overall rate of synthesis and delivery of the sum of the two sterols into the serum was reduced by drug treatment.

Representative results are shown in Figures 5 and 6. In Figure 6 there was no lowering effect of MER-29 on the incorporation of label into serum sterols. The general shape of the curves is little affected by treatment with MER-29. As can be seen from the results in Table III, most of

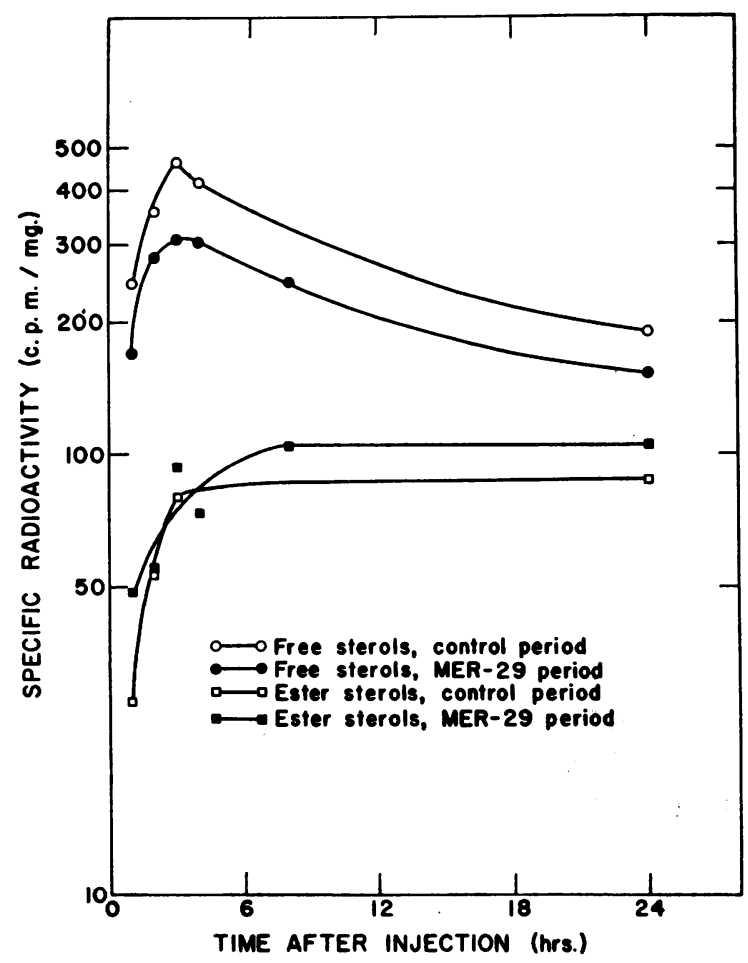

Fig. 5. SPeCific Radioactivity of FREe AND ESTeriFied UNFRACTIONATEd STERols in SERUM OF Patient M.J.C. DURING CONTROL AND MER-29 PERIODS,

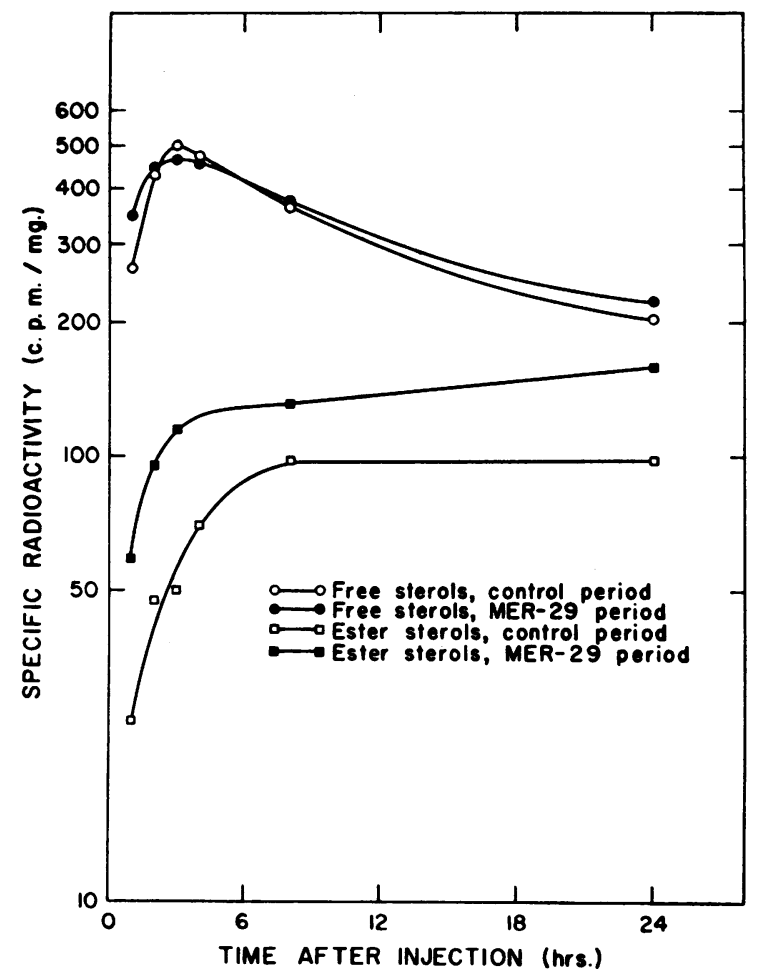

Fig. 6. SPECIFIC RAdIOACTIVITY OF FREE AND ESTERIFied UNFRACTIONATED STEROLS IN SERUM OF PATIENT L.J.McC. DURING CONTROL AND MER-29 PERIODS.

the radioactivity in the serum sterols during the first few hours of each experiment during drug treatment was present as desmosterol. The fact that the specific radioactivtiy of the ester sterol approaches the specific radioactivity of the free sterols at similar rates during experimental and control periods indicates, then, that the esterification of desmosterol proceeds at a rate comparable with that for esterification of cholesterol in the normal individual. This is consistent with the analyses for free to ester ratio discussed above, which indicate that the steady state degree of esterification of desmosterol is comparable with that of cholesterol.

Comparison of the specific radioactivities of serum free sterols 3 hours after injection of radioactive mevalonate, during a control period on the one hand and during MER-29 treatment on the other hand, shows a quantitatively variable but qualitatively consistent difference. On the average, the peak specific radioactivity during treatment was 16 per cent lower than that during the control period (Table IV). During the period of 
TABLE IV

Specific radioactivity and total radioactivity of unfractionated serum sterols 3 hours after 2-C $C^{14}$-mevalonate injection during a control period and during treatment with $M E R-29$

\begin{tabular}{|c|c|c|c|c|c|c|}
\hline \multirow[b]{2}{*}{ Patient } & \multicolumn{2}{|c|}{$\begin{array}{l}\text { Specific radioactivity of } \\
\text { unfractionated serum free } \\
\text { sterols } 3 \mathrm{hrs} \text { after injec- } \\
\text { tion of } 2-C^{14} \text {-mevalonate }\end{array}$} & \multirow[b]{2}{*}{ Difference } & \multicolumn{2}{|c|}{$\begin{array}{l}\text { Total radioactivity (unfrac- } \\
\text { tionated serum free sterols } \\
100 \mathrm{ml} \text { serum) } 3 \mathrm{hrs} \text { after } \\
\text { injection of } 2-\mathrm{C}^{14} \text {-mevalonate }\end{array}$} & \multirow[b]{2}{*}{ Difference } \\
\hline & $\begin{array}{l}\text { Control } \\
\text { period }\end{array}$ & $\begin{array}{c}\text { MER-29 } \\
\text { period }\end{array}$ & & $\begin{array}{l}\text { Control } \\
\text { period }\end{array}$ & $\underset{\text { period }}{\text { MER-29 }}$ & \\
\hline \multirow{3}{*}{$\begin{array}{l}\text { P.J.B. } \\
\text { W.F.B. } \\
\text { M.V.B. } \\
\text { M.J.C. } \\
\text { L.J.McC. } \\
\text { G.B. }\end{array}$} & \multicolumn{2}{|c|}{$\mathrm{cpm} / \mathrm{mg}$} & $\%$ & \multicolumn{2}{|c|}{$\mathrm{cpm} / 100 \mathrm{ml}$} & $\%$ \\
\hline & $\begin{array}{l}501 \\
616 \\
650 \\
461 \\
501 \\
411\end{array}$ & $\begin{array}{l}448 \\
545 \\
660 \\
308 \\
468 \\
254\end{array}$ & $\begin{array}{l}-11 \\
-12 \\
+2 \\
-33 \\
-7 \\
-38\end{array}$ & $\begin{array}{l}24,000 \\
38,200 \\
57,200 \\
22,100 \\
31,500\end{array}$ & $\begin{array}{l}17,900 \\
32,700 \\
50,800 \\
12,300 \\
25,700\end{array}$ & $\begin{array}{l}-25 \\
-14 \\
-11 \\
-44 \\
-18\end{array}$ \\
\hline & & & Mean - 16.5 & & & Mean -22.4 \\
\hline
\end{tabular}

MER-29 treatment, however, the absolute concentration of free sterols was lower than during the control period. Consequently, the difference in total radioactivity in the serum free sterols is even greater. Analyzed in this way, the synthesis and delivery of radioactive sterol to the serum was 22 per cent less during treatment.

\section{DISCUSSION}

Treatment with MER-29 in this limited series of cases led consistently to a marked decrease in the true cholesterol concentration in the serum (mean depression, 34 per cent). There was a simultaneous appearance of desmosterol in the serum at concentrations generally ranging from 25 to $55 \mathrm{mg}$ per $100 \mathrm{ml}$. In a patient with familial hypercholesterolemia and xanthoma tendinosum, the desmosterol concentration in the serum rose to well over $100 \mathrm{mg}$ per $100 \mathrm{ml}$. In this case the total serum sterol level actually rose slightly under treatment. If this case is excluded from the results, the mean drop in true sterol level was 16 per cent (range 0 to 23). These results cannot be directly compared with those of most of the clinical trials reported in the literature, because the investigators, not yet being aware of the occurrence of desmosterol in the serum and the analytical problem posed by it, have generally used simpler methods based on the Liebermann-Burchard reaction (25-27). Because of the low color yield given by desmosterol, use of such methods gives a result that is too low for the true serum sterol level. In the present series, for example, the change in serum sterol level as a result of treatment, estimated by use of the LiebermannBurchard reaction, would have been 23 per cent rather than the true change of 16 per cent. Recently, Hollander, Chobanian and Wilkins (28) reported results in a series of patients in whom the true total serum sterol level was determined by measuring total digitonin-precipitable sterols gravimetrically. In 12 patients treated for 2 to 47 weeks they found a mean drop in true sterol level of 17 per cent and estimated desmosterol levels ranging from 8 to $83 \mathrm{mg}$ per $100 \mathrm{ml}$. These results and those of the present study are in rather good agreement.

Any interpretation of the therapeutic significance of the study depends importantly upon whether desmosterol is considered to be equipotential with cholesterol as an atherogenic agent or whether its atherogenicity is different from that of cholesterol. As yet there is no experimental basis for deciding objectively on an answer to this problem. Still, it is worthy of note that desmosterol is remarkably like cholesterol in many of its properties. Its physical properties are similar to the point that separation by ordinary methods is extremely difficult. The distribution of desmosterol among the lipoprotein fractions is comparable with that of cholesterol (29). The rate of esterification of desmosterol, as shown here, is quite comparable with the rate of esterification of cholesterol in the same individual and the steady state free/ester ratio for desmosterol is the same as that for cholesterol. Animal studies have shown that, with high dosages of MER-29, desmosterol represents a major sterol component 
in many body tissues (18), indicating that it can replace cholesterol in the structural components of tissues, including red blood cells. All of these points taken together make it seem unlikely that the rate of deposition of desmosterol into atheromata will be found to be significantly different from that of cholesterol. At least until there is evidence to the contrary, the most reasonable hypothesis is that the two sterols are equipotential in atherogenicity.

Should this be the case, then the results of treatment must be evaluated on the basis of changes in total sterol level. These changes are variable from patient to patient, and it is important to recognize that some patients show no response or even an increase in total sterols. On the other hand, there are some patients in whom the total sterol level drops significantly, and the mean drop is in the neighborhood of 15 per cent. This degree of response compares unfavorably with the therapeutic responses that have been obtained using dietary treatment with unsaturated fat, or low fat diets, or with nicotinic acid (30-32).

In view of what appears to be a very marked inhibition of endogenous cholesterol production, it might have been anticipated that responses of cholesterol level would be exaggerated in the absence of exogenous cholesterol. Although only a few patients are available for comparison, it is of interest to note that there appeared to be no strikingly different response in patients on a diet devoid of cholesterol than in the patients receiving exogenous cholesterol (1).

The results of the present study lead us to conclude that the mechanism of action of MER-29 in man is, as in experimental animals, an inhibition of the reduction of desmosterol to cholesterol. The conclusion is supported by the accumulation of desmosterol in the serum and in the red blood cells during treatment. It is further supported by the isotopic data showing that, after injection of $2-\mathrm{C}^{14}$-mevalonic acid, the specific radioactivity of desmosterol in the serum is one to two orders of magnitude higher than that of cholesterol in the serum. These specific radioactivities did not approach each other until about 2 weeks after injection of the labeled precursor, indicating that the degree of inhibition is marked.

The studies, in which the rate of appearance of radioactivity in unfractionated serum sterols (desmosterol plus cholesterol) was measured, are difficult to interepret. The peak specific radioactivity during treatment with MER-29 was slightly lower (mean 16.5 per cent). The results when expressed in terms of the total radioactivity in circulating sterols showed a somewhat more impressive difference (mean 24.4 per cent). Whichever way the results are expressed, there does appear to be an inhibition in the rate of synthesis of labeled sterols and their delivery into the serum. However, the percentage inhibition is relatively small despite the fact that the block in conversion of desmosterol to cholesterol appears to be quite effective, as shown by the slowness with which the specific radioactivity of cholesterol rises (Figure 4). One tentative interpretation must be that, although there is a significant degree of inhibition of the conversion of desmosterol to cholesterol, leading to a reduction in serum cholesterol levels, the decreased rate of delivery of cholesterol into the serum is virtually compensated by the increased rate of delivery of desmosterol. The interpretation is complicated by the facts that the pool of desmosterol is smaller than the pool of cholesterol and that the exchange of each of the two labeled sterols between tissue compartments may be proceeding at a quite different rate. Of particular relevance is the rate at which labeled sterol, newly synthesized in the liver, gets into the serum by isotopic exchange reactions relative to the rate at which it enters the serum compartment as a result of net secretion of sterol-containing lipoprotein molecules.

MER-29 is the first pharmacological inhibitor of cholesterol biosynthesis for which a definite site of action has been established. The drug appears to be free of at least short-term undesirable side effects, and it depresses total serum sterol concentrations. However, because of the accumulation of desmosterol, the response in terms of total sterol levels is not dramatic. Moreover, the long-term biological effects of desmosterol remain to be evaluated.

\section{SUMMARY}

1. In the nine cases studied, treatment with MER-29 was always associated with the appearance of desmosterol in the serum, which accounted for 19 to 43 per cent (average 27) of the total circulating sterols. The free to total ratio for 
circulating desmosterol was not significantly different from that of cholesterol.

2. All of the patients treated showed a marked drop in serum cholesterol concentration (average 34.0 per cent) but because of the simultaneous accumulation of desmosterol, total sterol levels were depressed by only 15 per cent.

3. A method for determining desmosterol in the presence of cholesterol is described. It is demonstrated that the usual analytical procedures yield low values for total sterol levels when desmosterol is present.

4. After intravenous injection of 2-C $\mathrm{C}^{\mathbf{1 4}}$-mevalonate in patients under treatment with MER-29, the specific radioactivity of serum desmosterol was at least an order of magnitude higher than that of cholesterol. The specific radioactivities of the two sterols did not become equal until 2 weeks after injection of labeled mevalonate.

5. The specific radioactivity of esterified desmosterol, low during the early hours, rose and became equal to the specific radioactivity of free desmosterol at 24 to 48 hours after injection of labeled mevalonate.

6. After injection of 2-C ${ }^{14}$-mevalonate, the peak specific radioactivity and total radioactivity in the unfractionated serum sterols during treatment with MER-29 were significantly lower than during control periods.

7. It is concluded that the mechanism of action of MER-29 in man is to inhibit the reduction of desmosterol to cholesterol and that the depression of serum cholesterol levels and total serum sterol levels is attributable to this inhibition at the final step in cholesterol biosynthesis.

\section{REFERENCES}

1. Steinberg, D., Avigan, J., and Feigelson, E. B. Identification of 24-dehydrocholesterol in the serum of patients treated with MER-29. Progr. cardiovasc. Dis. 1960, 2, part 1, 586.

2. Avigan, J., Steinberg, D., Thompson, M. J., and Mosettig, E. Inhibition of conversion of 24-dehydrocholesterol to cholesterol by MER-29 (abstract). Fed. Proc. 1960, 19, 239.

3. Steinberg, D., and Fredrickson, D. S. Inhibitors of cholesterol biosynthesis and the problem of hypercholesterolemia. Ann. N. Y. Acad. Sci. 1956, 64, 579.

4. Curran, G. L. A rational approach to the treatment of atherosclerosis. Amer. Practit. 1956, 7, 1412.

5. Tomkins, G. M., Sheppard, H., and Chaikoff, I. L. Cholesterol synthesis by liver. IV. Suppression by steroid administration. J. biol. Chem. 1953, 203, 781.

6. Tomkins, G. M., Nichols, C. W., Jr., Chapman, D. D., Hotta, S., and Chaikoff, I. L. Use of $\Delta^{4}$-cholesterone to reduce the level of serum cholesterol in man. Science 1957, 125, 936.

7. Steinberg, D., Fredrickson, D. S., and Avigan, J. Effects of $\Delta^{4}$-cholestenone in animals and in man. Proc. Soc. exp. Biol. (N. Y.) 1958, 97, 784.

8. Nichols, C. W., Jr., Lindsay, S., and Chaikoff, I. L. Production of arteriosclerosis in birds by the prolonged feeding of dihydrocholesterol. Proc. Soc. exp. Biol. (N. Y.) 1955, 89, 609.

9. Steinberg, D., and Fredrickson, D. S. Inhibition of lipid synthesis by alpha-phenyl-N-butyrate and related compounds. Proc. Soc. exp. Biol. (N. Y.) 1955, 90, 232.

10. Fredrickson, D. S., and Steinberg, D. Failure of alpha-phenylbutyrate and beta-phenylvalerate in treatment of hypercholesterolemia. Circulation 1957, 15, 391.

11. Curran, G. L., Azarnoff, D. L., and Bolinger, R. E. Effect of cholesterol synthesis inhibition in normocholesteremic young men. J. clin. Invest. 1959, 38, 1251.

12. Bergen, S. S., Jr., Van Itallie, T. B., and Sebrell, W. H. Hypocholesteremic effect in man of benzmalecene: An inhibitor of cholesterol biosynthesis. Proc. Soc. exp. Biol. (N. Y.) 1960, 103, 39.

13. Blohm, T. R., and MacKenzie, R. D. Specific inhibition of cholesterol biosynthesis by a synthetic compound (MER-29). Arch. Biochem. 1959, 85, 245.

14. Blohm, T. R., Kariya, T., and Laughlin, M. W. Effects of MER-29, a cholesterol synthesis inhibitor, on mammalian tissue lipides. Arch. Biochem. 1959, 85, 250.

15. Avigan, J., Steinberg, D., Thompson, M. J., and Mosettig, E. Mechanism of action of MER-29, an inhibitor of cholesterol biosynthesis. Biochem. biophys. Res. Com. 1960, 2, 63.

16. Avigan, J., Steinberg, D., Thompson, M. J., and Mosettig, E. The mechanism of action of MER29. Progr. cardiovasc. Dis. 1960, 2, 525.

17. Abell, L. L., Levy, B. B., Brodie, B. B., and Kendall, F. E. A simplified method for the estimation of total cholesterol in serum and demonstration of its specificity. J. biol. Chem. 1952, 195, 357.

18. Avigan, J., Steinberg, D., Vroman, H. E., Thompson, M. J., and Mosettig, E. Studies of cholesterol biosynthesis. I. The identification of desmosterol in serum and tissues of animals and man treated with MER-29. J. biol. Chem. 1960, 235, 3123.

19. Bergmann, W., and Dusza, J. P. Contribution to the study of marine products. XLVI. 24- and 25Dehydrocholesterol. J. org. Chem. 1958, 23, 459.

20. Idler, D. R., and Baumann, C. A. Skin sterols. II. Isolation of $\Delta^{7}$-cholestenol. J. biol. Chem. 1952, 195,623 . 
21. vanden Heuvel, W. J. A., Sweeley, C. C., and Horning, E. C. Separation of steroids by gas chromatography. J. Amer. chem. Soc. 1960, 82, 3481.

22. Zilversmit, D. B., Entenman, C., and Fishler, M. C. On the calculation of "turnover time" and "turnover rate" from experiments involving the use of labeling agents. J. gen. Physiol. 1943, 26, 325.

23. Hellman, L., Rosenfeld, R. S., Eidinoff, M. L., Fukushima, D. K., and Gallagher, T. F., and Wang, C. I., and Adlersberg, D. Isotopic studies of plasma cholesterol of endogenous and exogenous origins. J. clin. Invest. 1955, 34, 48.

24. Eckles, N. E., Taylor, C. B., Campbell, D. J., and Gould, R. G. The origin of plasma cholesterol and the rates of equilibration of liver, plasma, and erythrocyte cholesterol. J. Lab. clin. Med. 1955, 46, 359.

25. Hollander, W., and Chobanian, A. The effects of an inhibitor of cholesterol biosynthesis, Triparanol (MER-29) in subjects with and without coronary artery disease. Boston med. Quart. 1959, 10, no. 2, 37.
26. Oaks, W., Lisan, P., and Moyer, J. M. Inhibition of cholesterol synthesis with the use of Mer-29. A.M.A. Arch. intern. Med. 1959, 104, 527.

27. Proceedings of Conference on MER-29 (Triparanol), I. S. Wright, Chairman, Princeton, N. J., December 16-17, 1959. Progr. cardiovasc. Dis. 1960, 2, no. 6 (part I), suppl.

28. Hollander, W., Chobanian, A. V., and Wilkins, R. W. The effects of Triparanol (MER-29) in subjects with and without coronary artery disease. J. Amer. med. Ass. 1960, 174, 5.

29. Avigan, J., and Steinberg, D. Unpublished results.

30. Brown, H. B., and Page, I. H. Lowering blood lipid levels by changing food patterns. J. Amer. med. Ass. 1958, 168, 1989.

31. Boyer, P. A., Jr., Lowe, J. T., Gardier, R. W., and Ralston, J. D. Effect of a practical dietary regimen on serum cholesterol level. J. Amer. med. Ass. 1959, 170, 257.

32. Parsons, W. B., Jr., and Flinn, J. H. Reduction of serum cholesterol levels and beta-lipoprotein cholesterol levels by nicotinic acid. A. M. A. Arch. intern. Med. 1959, 103, 783. 